\title{
A Postmortem Study of a Patient with Low Titer Nicotinic Acetylcholine Receptor Ganglionic Antibody: Implications for Clinical Neurologic Disease
}

\author{
David S. Younger \\ City University of New York, School of Medicine, Graduate School of Public Health and Health Policy, New York, NY, USA \\ Email: youngd01@nyu.edu
}

How to cite this paper: Younger, D.S. (2019) A Postmortem Study of a Patient with Low Titer Nicotinic Acetylcholine Receptor Ganglionic Antibody: Implications for Clinical Neurologic Disease. World Journal of Neuroscience, 9, 71-75. https://doi.org/10.4236/wjns.2019.93005

Received: May 1, 2019

Accepted: June 16, 2019

Published: June 19, 2019

Copyright $\odot 2019$ by author(s) and Scientific Research Publishing Inc. This work is licensed under the Creative Commons Attribution International License (CC BY 4.0).

http://creativecommons.org/licenses/by/4.0/ (c) (i) Open Access

\begin{abstract}
Small fiber polyneuropathy is a well-recognized syndrome mitigated by somatic sensory afferent and autonomic efferent nerve fibers that respectively mediate pain, heat and cold temperature afferent and autonomic efferent function in the skin. A patient with low serum titers of neuronal acetylcholine receptor ganglionic antibodies and autonomic failure had symptomatic small fiber polyneuropathy late in life in the setting of autoimmune dementia and encephalopathy and prostate cancer. Large and small fiber polyneuropathy and dysautonomia were detected in routine electrodiagnostic and autonomic laboratory studies, and epidermal nerve fiber analysis of the calf and thigh. Clinical improvement for one year concomitant with intravenous immune globulin therapy preceded a clinical decline in neurocognitive function and death. Postmortem examination showed typical features of Alzheimer disease with neuropathic neuropathological changes in the peripheral nervous system, and viable autonomic ganglia consistent with a channelopathy mechanism involving postsynaptic neuronal nAChRs.
\end{abstract}

\section{Keywords}

Dysautonomia, Ganglionic Receptor Antibodies, Small Fiber Neuropathy

\section{Introduction}

Small-fiber polyneuropathy (SFPN) is a disorder of thinly myelinated A- $\delta$ and unmyelinated $\mathrm{C}$ fibers that classically affects somatic sensory and autonomic functions [1] [2]. There is no known association of nicotinic acetylcholine receptor (nAChR) ganglionic antibodies in patients screened with SFPN [3]. Nei- 
ther is there a known association between $\mathrm{nAChR}$ ganglionic antibodies, autoimmune autonomic failure (AAF) or SFPN and presumed autoimmune dementia and encephalopathy (ADE) that brought the patient to medical attention.

\section{Patient Report}

In the summer of 2016, a 78-year-old man with numbness, tingling and limb pain had lightheadedness and cognitive decline for one year. He was treated for prior Lyme exposures. Neurological examination in June 2016 showed impaired short-term registration, stocking vibratory and cold temperature sensory loss, Romberg sign, tandem imbalance, grade $4+/ 5$ leg distal leg strength, hyporeflexia, and Babinski signs. Autonomic testing (WR-Testworks, Minnesota [MN]) showed a supine systolic blood pressure (SBP) of $134 \mathrm{mmHg}$ and heart rate (HR) of 57 beats per minute (bpm). Head-up tilting led to symptomatic orthostasis with a minimum SBP of $70 \mathrm{mmHg}$ at 3.6 minutes without a compensatory $\mathrm{HR}$ change, followed by a period of prolonged hypotension and near-syncope. Electrodiagnostic studies showed a distal left fibula compound muscle action potential amplitude of $0.3 \mathrm{mV}$ and motor nerve conduction velocity of 30 meters per second. Bilateral tibial and right fibular motor, and bilateral superficial fibular and sural sensory responses were absent. Concentric needle electromyography showed chronic neurogenic changes without active or chronic denervation at rest. Epidermal nerve fiber densities (ENFD) (Figure 1(A)) were consistent with a non-length dependent process (mean left calf: $3.2 \mathrm{ENF} / \mathrm{mm}$; mean left thigh 2.3 ENF/mm) consistent with SFPN. Left sural nerve biopsy showed a demyelinating component in $32.7 \%$ of teased nerve fibers; with excessive thinly myelinated fibers in epoxy resin sections, consistent with chronic inflammatory demyelinating polyneuropathy (CIDP). Left soleus muscle biopsy (Figure 1(B)) showed mild neurogenic changes and perivascular inflammation. Blood studies showed total prostate specific antigen (PSA) $4.6 \mathrm{ng} / \mathrm{mL}$ (normal $\leq 4 \mathrm{ng} / \mathrm{mL}$ ). Whole body ${ }^{18 f}$ Fluorodeoxyglucose positron emission tomography (PET) showed temporoparietal and frontal lobe hypometabolism, with a focus of intracapsular prostatic cancer, later confirmed on magnetic resonance imaging of the pelvis. However, there were discernible metastatic foci. Cerebrospinal fluid (CSF) protein was $65 \mathrm{mg} / \mathrm{dL}$ (normal $>50 \mathrm{mg} / \mathrm{dL}$ ) without inflammation or infection. Mayo Clinic (MN) Autoimmune Dementia panel in serum and CSF showed a serum $\mathrm{nAChR}$ ganglionic antibody level of $0.05 \mathrm{nmol} / \mathrm{L}$ (normal $\leq 0.02 \mathrm{nmol} / \mathrm{L}$ ) with otherwise normal values. Athena Diagnostics (Massachusetts [MA]) ADmark ${ }^{\circledR}$ analysis was inconclusive for symptomatic Alzheimer disease (AD) and consistent with $\mathrm{ADE}$. The patient was treated with six months of 2 grams per kilogram intravenous immune globulin (IVIg) with stabilization of his disorder. However, after discontinuation of IVIg was followed by continued deterioration, and death in June 2018 in hospice.

Postmortem examination at New York University Langone Health showed foci of intracapsular well-differentiated prostatic adenocarcinoma; and frequent 


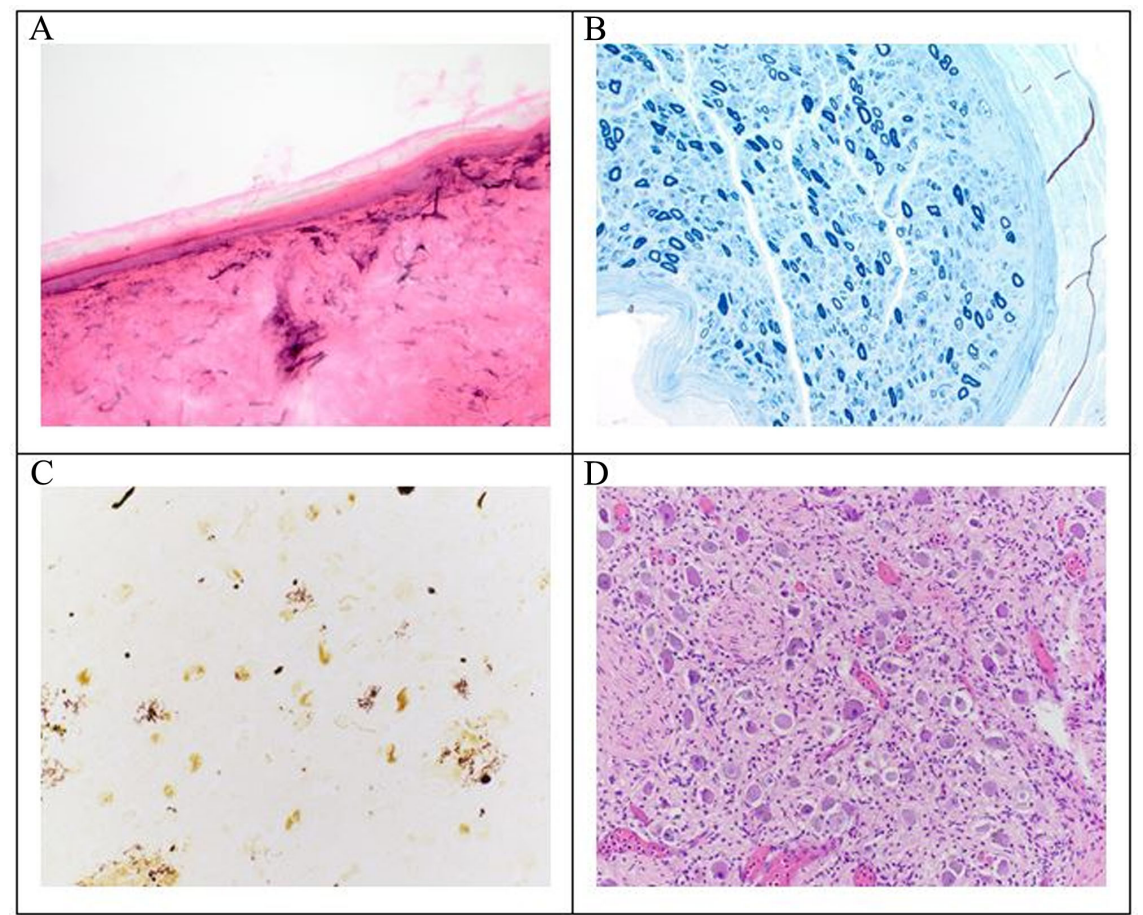

Figure 1. (A) Epidermal nerve fiber analysis. There are reduced densities of epidermal nerve fibers in the calf and thigh (shown) (PGP 9.5 \& Eosin, 200x); (B) Epoxy resin transverse section of nerve. There is a moderate degree of axonal loss, and occasional regenerative clusters and thinly myelinated fibers in each fascicle suggesting segmental remyelination (Toluidine blue, $\times 600$ ); (C) Postmortem hippocampus brain section. Typical plaques and tangles of Alzheimer disease are evident in the CA1 subsector (Bielschowsky silver stain, 40x); (D) Postmortem autonomic ganglia. An autonomic ganglia shows well-populated neurons (Hematoxylin and eosin, Luxol, 20×).

neuritic plaques and neurofibrillary tangles (Figure $1(\mathrm{C})$ ) in sections of hippocampus, amygdala and association cortex without microglial nodules or inflammation. Spinal nerve roots and peripheral nerves showed patchy myelin loss. Autonomic ganglia were unremarkable (Figure 1(D)).

\section{Discussion}

This is the first and only postmortem examination of a patient with nAChR ganglionic antibodies. Circulating nAChR ganglionic antibodies are associated with autoimmune autonomic neuropathy and ganglionopathy, and AAF [4] [5] and viable autonomic ganglia, as in the present case, keeping with a mechanism of channelopathy involving postsynaptic neuronal nAChRs [6] [7] [8]. In life, this patient was thought to have ADE on the basis of circulating $\mathrm{nAChR}$ ganglionic antibodies and occult malignancy, with a stabilizing response of IVIg, however, postmortem examination was consistent was AD. Similar to AAF due to circulating $\mathrm{nAChR}$ antibodies, there is a paucity of pathologically-proven cases of ADE to facilitate meaningful comparisons of the expected features of either syndrome with a given serum antibody titer. Nonetheless, $\mathrm{nAChR}$ antibody titers predict the clinical features of AAF in life [4] [9], and possibly the cognitive im- 
pairment of reversible early and late-onset ADE or associated AD [10] [11].

\section{Conclusion}

Extraordinary advances have occurred in the importance of studying nAChR ganglionic antibodies. This patient report establishes its relevance to central, peripheral and autonomic nervous system aspects of neurological disease.

\section{Acknowledgements}

Kurenai Tanji MD, Professor of Pathology and Cell Biology (in Neurology), Columbia University provided figures and legends for the ENFA and epoxy resin section of nerve. Christopher M. William MD, PhD, Assistant Professor, Department of Pathology and Neurology, New York University, provided figures and legends for the illustrated pathology of autopsy brain sections illustrated. Dr. Steven Vernino, Chairman of Neurology, University of Texas Southwestern Hospital Dallas, provided helpful comments.

\section{Disclosure}

The author does not have conflicts of interest to disclose. The patient's family consent to this publication.

\section{References}

[1] Bakkers, M., Faber, C.G., Hoeljmakers, J.G.J., et al. (2014) Small-Fibers, Large Impact: Quality of Life in Small-Fiber Neuropathy. Muscle Nerve, 49, 329-336. https://doi.org/10.1002/mus.23910

[2] Novak, V., Freimer, M.L., Kissel, J.T., et al. (2001) Autonomic Impairment in Painful Neuropathy. Neurology, 56, 861-868. https://doi.org/10.1212/WNL.56.7.861

[3] Sandroni, P. and Low, P.A. (2009) Other Autonomic Neuropathies Associated with Ganglionic Antibody. Autonomic Neuroscience, 146, 13-17.

https://doi.org/10.1016/j.autneu.2008.10.022

[4] Cutsforth-Gregory, J.K., McKeon, A., Coon, E.A., et al. (2018) Ganglionic Antibody Level as a Predictor of Severity of Autonomic Failure. Mayo Clinic Proceedings, 93, 1440-1447. https://doi.org/10.1016/j.mayocp.2018.05.033

[5] Nakane, S., Mukaino, A., Higuchi, O., et al. (2018) Autoimmune Autonomic Ganglionopathy: An Update on Diagnosis and Treatment. Expert Review of Neurotherapeutics, 18, 953-965. https://doi.org/10.1080/14737175.2018.1540304

[6] Vernino, S., Lindstrom, J., Hopkins, S., et al. (2008) Characterization of Ganglionic Acetylcholine Receptor Autoantibodies. Journal of Neuroimmunology, 197, 63-69. https://doi.org/10.1016/j.jneuroim.2008.03.017

[7] Vernino, S., Low, P.A. and Lennon, V.A. (2003) Experimental Autoimmune Autonomic Neuropathy. Journal of Neurophysiology, 90, 2053-2059. https://doi.org/10.1152/jn.00408.2003

[8] Vernino, S., Low, P.A., Fealey, R.D., et al. (2000) Autoantibodies to Ganglionic Acetylcholine Receptors in Autoimmune Autonomic Neuropathies. The New England Journal of Medicine, 343, 847-855.

https://doi.org/10.1056/NEJM200009213431204 
[9] Gibbons, C.H. and Freeman, F. (2009) Antibody Titers Predict Clinical Features of Autoimmune Autonomic Ganglionopathy. Autonomic Neuroscience: Basic and Clinical, 146, 8-12. https://doi.org/10.1016/j.autneu.2008.11.013

[10] Baker, S.K., Morillo, C. and Vernino, S. (2009) Autoimmune Autonomic Ganglionopathy with Late-Onset Encephalopathy. Autonomic Neuroscience: Basic and Clinical, 146, 29-32. https://doi.org/10.1016/j.autneu.2008.10.016

[11] Gibbons, C., Centi, J., Vernino, S., et al. (2012) Autoimmune Autonomic Ganglionopathy with Reversible Cognitive Impairment. Archives of Neurology \& Psychiatry, 69, 461-466. https://doi.org/10.1001/archneurol.2011.2372 